\title{
Analysis of Isolated and Non-Isolated Zeta Converter based on Battery Charger
}

\author{
Bhuvaneswari K \\ PG Scholar, Dept. of EEE, \\ Govt. Engineering College, Barton Hill, \\ Thiruvananthapuram
}

\author{
Dr. Sunila M S \\ Associate Professor \\ Dept. of EEE,Govt.Engineering College, Barton Hill, \\ Thiruvananthapuram
}

\begin{abstract}
Conventional battery chargers are due to the nonlinear nature of a diode-bridge rectifier used for the AC-DC conversion. A single phase non-isolated zeta converter topology is designed and implemented for charging a 100 $\mathrm{Ah}, 48 \mathrm{~V}$ lead acid battery[1].The challenges of non- isolated zeta converter topology is reduced heat loss and smooth charge of battery. The simulation results shows that THD of the input current is low as compared to iso- lated zeta converter.The proposed converter is controlled using the sliding mode controller(SMC). By proper tun- ing the controller changes the charging mode from con- stant current to constant voltage. The analysis between the isolated and non-isolated battery shows that the non- isolated battery charger can achieve the increasing the state of charge and smooth charging. percent italics mode
\end{abstract}

\section{INTRODUCTION}

The major concerns with the conventional vehicles are the phenomenal hike in conventional fuel prices as well as public health issues[1].EV are constantly influencing the modern transportation system paid to their energy sav- ing mechanism and reduced the pollution in the environ- ment. The lead acid batteries are normally used for heavy duty operations involving many 100 s of amps. The charge these batteries we specifically need chargers rated to han-dle high ampere charging levels for long periods of time. The high power lead acid battery used for charging large high current lead acid batteries in the order of 100 to 500 Ah,once the battery gets fully charged. Through nonisolated zeta converter is similar to that of a buck/boost converter, it has an advantages of non-inverted output. It has a wider range of duty ratio than any other con- verter. The converter exhibit improved power factor,low input current distortion low output current ripple and wide output power range[11]. A non-isolated zeta converter is fourth order DC-DC converter capable of amplifying and reducing the input voltage levels without inverting the polarity. The SOC is defined as the percentage of the remained charge inside the battery o the full charge, which is one of the most important parameter on batteries. Accurate SOC estimation owns a great of significant to the vehicle. Its estimation is a key research area and it should be exploited with in designed limits. Common SOC estimations are current integration method,open cir- cuit voltage method,discharge test method,resistance prediction method. The non-isolated zeta converter is operated in discontinuous conduction mode so it reduce the diode reverse recovery time and zero current switch- ing. The low transformer is not presented so the system weight and losses are reduced and also improve the efficiency.The sliding mode controller (SMC) is a nonlinear control method that alters the dynamics of a nonlinear system by application of a discontinuous control signal that forces the system to slid along a cross of the system's normal behavior.

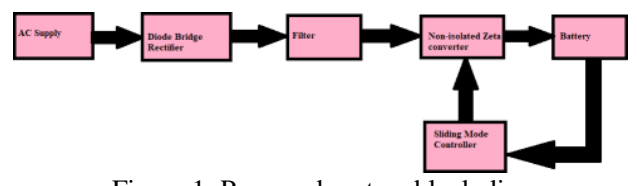

Figure 1: Proposed system block diagram

\section{PROPOSED NON-ISOLATED ZETA CON-}

VERTER:CONFIGURATION AND OPERA- TION

It consist of a Diode bridge rectifier powered by a single phase AC supply at its input. An uncontrolled DC voltage is breed at the output of the rectifier. This uncontrolled DC voltage works as the input of non-isolated zeta con- verter. This converter provides a controlled and regulated DC output voltage as well as the mains current is sinu- soidal which conform the improved Power Quality(PQ) standard. The major concerns of an EV battery charger is the presence of low AC ripple constant in charging current. The ripple current flow through the battery be- cause of the huge capacitance in the battery circuit and it taken care of the reliable battery operation. So it increases the internal temperature of the battery due to excess heat. Therefore large amount of ripple current is reduced life cycle of the battery. So it designing the AC- DC converter of battery charger to meet the permissible ripple current requirements of the battery with use of an non-isolated topology. A nonisolated zeta converter is a fourth or- der non-linear system with regard to energy input and the same as sen in the buck- boost converter and with regard to the output. A nonisolated zeta converter modes are depending on inductance value, load resistance and op- erating frequency,here only continuous conductor current iL1.The analysis uses the following assumption,

Semiconductors switching devices are considered to be ideal.

- Converter operating in continuous current mode.

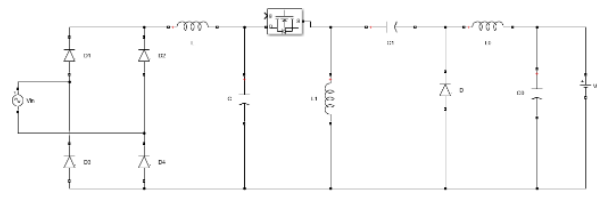

Figure 2: Proposed circuit diagram 
- Line frequency ripple in the DC voltage is neglected.

\subsection{Operation}

Mode-1:

The first mode is obtained when the switch is ON and instantaneously, the diode D is OFF condition as shown in fig(3). During this period,the current flow through the inductor L1 and L2 are drawn from the voltage source Vs. The capacitor $\mathrm{C} 2$ is charging condition. This mode is the charging mode.

Mode-2:

In this mode of operation starts when the switch is OFF condition and diode D is ON position as shown in fig(3). In this mode of operation is the inductor L2 is transfer the stored energy into load R(battery). So the battery going to discharging mode.

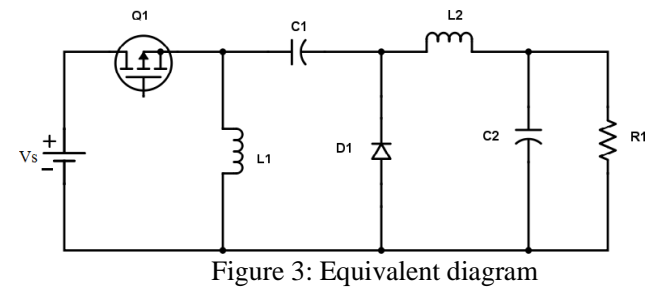

not more an hour. Basically it must have the following parameters for the safe charging which does not required special step chargers.

- Fixed current or constant current (1/10th of battery Ah rating)

- Fixed voltage or constant voltage (17\% higher than battery printed voltage)

- Over charge protection (cut-off when battery gets charged to the above level)

- Float gets charge (optional, not compulsory at all)

\section{State space equation}

The DC-DC voltage non-isolated zeta converter is assumed to the continuous conduction mode(CCM). It exist two circuit states with in one switch period T. First state condition when switch is turned on (DT) and another switch is turned off [(1-D)T]. The general state space mathematical model of the non-isolated zeta converters is given by

$$
\begin{aligned}
& X \cdot=A x+B U \\
& Y=C x+D U
\end{aligned}
$$

The second state condition the switch is off(1-D)T. In this mode the inductors L1,L2 are in discharging state. L1 is discharging its stored energy into the capacitor C1 and the inductor L2 transfer energy to the output section. Using ON state and OFF state equation, the system state

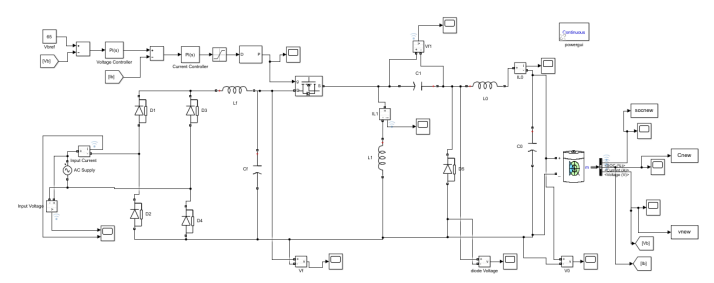

Figure 4: PI controller simulink block

space equivalent equation become to be,

$\left[\begin{array}{l}X 1 \\ X 2 \\ X 3 \\ X 4\end{array}\right]=\left[\begin{array}{cccc}0 & 0 & (1-D) / L 1 & 0 \\ 0 & 0 & D / L 2 & -1 / L 2 \\ (1-D) / C 1 & -D / C 1 & 0 & 0 \\ 0 & D / C 2 & 0 & -1 / C 2\end{array}\right]$
$\left[\begin{array}{l}x 1 \\ x 2 \\ x 3 \\ x 4\end{array}\right]+\left[\begin{array}{c}D / L 1 \\ D / L 2 \\ 0 \\ 0\end{array}\right]\left[\begin{array}{c}U \\ U \\ 0 \\ 0\end{array}\right]$

The output equation is $Y=x 4$ so the matrix form of output is, $\mathrm{Y}=\left[\begin{array}{llll}0 & 0 & 0 & 1\end{array}\right\rceil\left[\begin{array}{l}x 1 \\ x 2 \\ x 3 \\ x 4\end{array}\right\rceil$

\section{Simulation Result}

The performance of controller by reference load voltage variation is analyzed under the load variation is $48 \mathrm{~V}$ the output voltage, output current and state of charge can be regulated by the controller.

\subsection{PI controller}

The PI controller is use in this decades. It perform the satisfactorily during transient under limited operating range. The PI-controller gives the gate signal to the non-isolated zeta converter. This control signal is used for the unipolar PWM switching of the proposed non-isolated zeta converter. The uni-polar PWM switching signal has the advantages of low harmonic content in the output voltage.

The output current waveform of PI controller is easy to charge the battery but it will slow to reach the state of charge in full this result shown in fig(5). The output voltage waveform of PI controller shown in fig(6) and it 


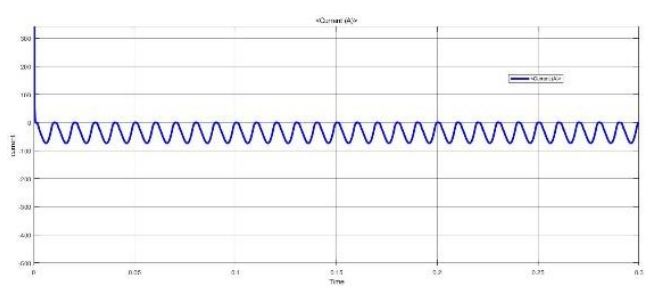

Figure 5: Output current wave form of PI controller

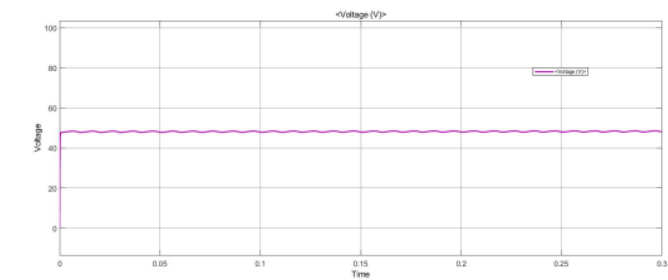

Figure 6: Output voltage wave form of PI controller

output voltage range is $48 \mathrm{~V}$. The THD of PI controller used non isolated zeta converter is $5.50 \%$ shown in fig(7). The THD percent in input current.

\subsection{Sliding mode controller}

The SMC shown the potential to be insensitive to the parameter variations and external disturbances. A nonisolated zeta converter is used to SMC in the closed loop control system shown in fig(8). The SMC surface value is zero this controller is satisfied.

$S=k_{p} e+k_{i} e+k_{d} e * * \quad *$

The output current wave form of SMC is charge in fast and the no distortion in output shown in fig(9). The out- put voltage is $48 \mathrm{~V}$ and in this voltage is used to refer- ence voltage to develop a uni-polar PWM switching sig-

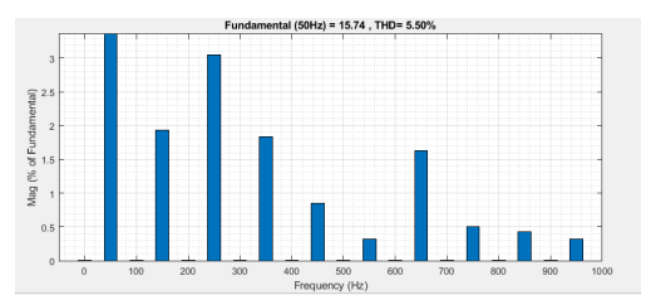

Figure 7: THD of PI controller

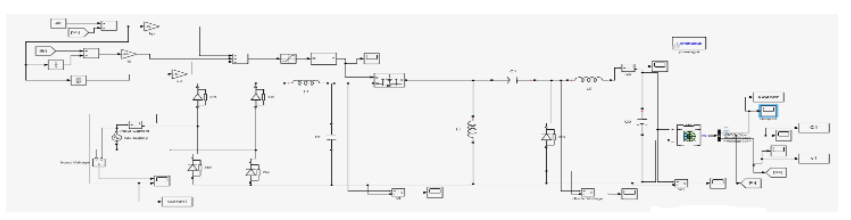

Figure 8: Sliding mode controller simulink block

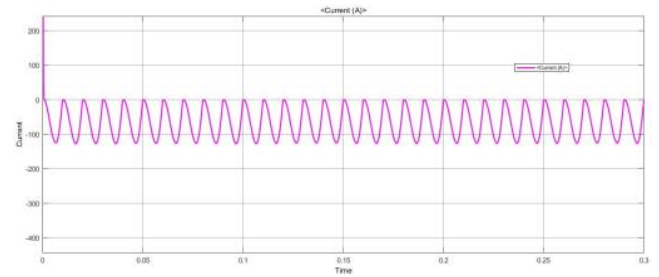

Figure 9: Output current wave form of sliding mode controller

nal shown in fig(10). This range of voltage level is controlled by the storage of the battery. The THD of input current is lower than the PI controller. The THD percentage is $0.01 \%$ shown in fig(11).

Comparison of the PI and sliding mode controller is shown in fig(12). In this figure result is state of charge comparison is explained. The SOC is easy and fast to reach the $100 \%$ range in the waveform. The SMC is fast to reach the full and PI controller is Reach in slowly. And in this condition SMC result is very smooth charging is regulated and the battery life time is increased.

\section{CONCLUSION}

The performance comparison between SMC and PI controller is done and simulation result using non isolated

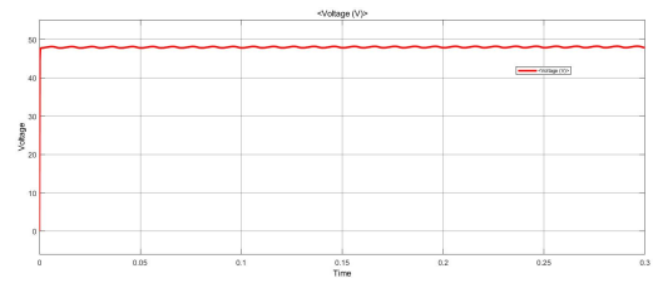

Figure 10: Output voltage wave form of sliding mode controller

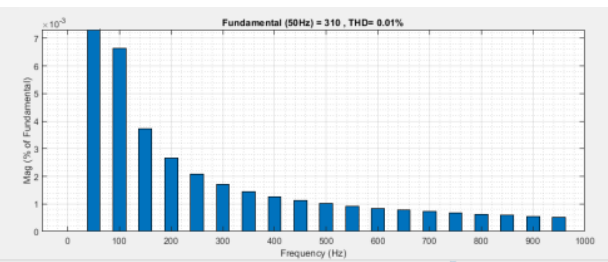

Figure 11: THD of sliding mode controller

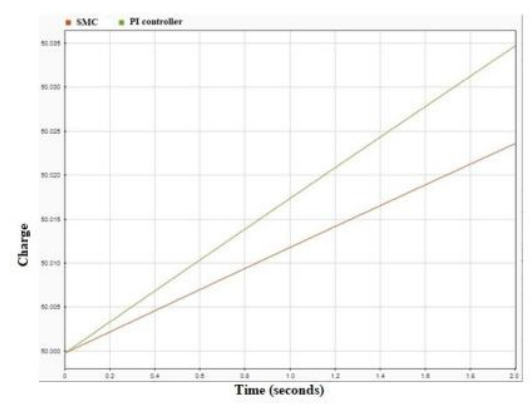

Figure 12: Comparison waveform of SOC 
zeta converter under the load voltage variation. The sliding mode controller used in proposed system is very fast to reach the state of charge in full compared to PI con- troller. The SMC is regulated the output voltage and out- put current and it under any disturbance in supply side or load side. The battery charge in smooth in SMC as com- pared to PI controller. The smoothing of battery charging it increases the life of battery.

\section{REFERENCES}

[1] Guangfu Ning, Radha Kushwaha, Bhim singh,'UPF- isolated zeta converter-based battery charger for electric vehicle ",in IEEE Journal.Electron.,vol.9, no.45,pp.103-112,Sep.2019.

[2] Lim, S., Otten, D.M., Perreault, D.J. "New AC-DC power factor correction architecture suitable for high- frequency operation",in IEEE Trans. Power Elec- tron., vol.31, (4), pp. 2937-2949,2016.

[3] Prasanna, U.R., Singh, A., Rajashekara, K. "Novel bidirectional single-phase single-stage isolated AC- DC converter with PFC for charging of electric ve- hicles",IEEE Trans. Transp. Electrif., vol.3, pp. 536- 544,2017.

[4] Yao, K., Wang, Y., Guo, J., et al. "Critical conduction mode boost PFC converter with fixed switching fre- quency control",IEEE Trans. Power Electron., vol.33, pp. 6845-6857,2018.

[5] Sumita Dhali, P.Nageshwara Rao, Praveen Mande, K.Venkateswara Rao, "PWM-based sliding mode controller for DC-DC boost converter," in IJERA ISSN, vol.2, Issue 1, Janfeb.2012,pp.616-623.

[6] V.S.C.Raviraj and P.C. Sen ,"Comparative study of proportionalintegral,sliding mode and fuzzy logic controllers for powe converters,"in IEEE trans. on industry application, vol.33, No.2, pp. 518-524, March-April ,1997.

[7] H. Eduardo Ariza Chacon, Edison Banguero,"Modelling, parameter identification, and experimental validation of a lead acid battery bank using evoluationary algorithms,"in journal, 2018 sep-7, pp. 1-14.

[8] Jinhao Meng, Guangzhao Luo."A simplified model based state of charge estimation approach for lithium- ion battery with dynamic linear model,"in IEEE trans on industrial electronics, 2018, vol.66.

[9] Wen-hua cui, Jie sheng wang and Yuan-yuan chen."Equivalent circuit model of lead acid battery in energy storage power station and its state of charge estimation based on extended kalman filtering method,"in journal, Jan 2018, pp. 504-517.
[10] Carlo taborelli, Simona onari, "State of charge esti- mation using extended kalman filters for battry man- agement system,"in IEEE inter. elect., 2014.

[11] Martin murnan, Adel Ghael,"A closer look at state of charge (SOC) and state of health( $\mathrm{SOH})$ estimation techniques for batteries,"in Journal, 2017, pp. 187- 518.

[12] Mariammal Thirumeni,Deepa Thangavelusamy,"Performance analysis of PI and SMC controlled Zeta converter,"in Inter.Journal., sep-2019, vol. 8, pp. 357-365.

[13] Chongqing piao, Mingliang Liu,"Study on stable es- timation method for lead acid battery SOC by ex- tended kalman filter,"in Inter. Journal, 2014, vol. 7, pp. 429-438.

[14] Yuqiang jin, Jianhong shi,"Simulation realization of sliding mode control for second order system with M language,"in Inter. confe. on elect. , 2016.

[15] Venkatanarayanan subramanian and saravanan manimaran,"Implementation of a sliding mode controller for single ended primary inductor converter,"in Jour- nal of power elect., Jan-2015,vol. 15, pp. 39-53.

[16] V. Suganya, S. vijayalakshmi, KR. Vairamani, K. Anudheebha,"Solar powered battery charger using sliding mode controller,"in Ijesc journal, 2016, vol. 6.

[17] E. Vuthchhay and C. Bunlaksananusorn,"Modeling and control of a zeta converter,"in IEEE confer. Power Electron., 2010. 